\title{
Integrating knowledge management with project management for project success
}

\author{
Anthony Yeong \\ Independent Consultant \\ Thou Than Lim \\ Decision Modelling Systems2
}

\begin{abstract}
This paper aims to study the improvement of project success in organizations by integrating knowledge management strategies with project management practices in a typical project lifecycle.
\end{abstract}

According to the Standish Group’s Chaos Report for 2009, only 32\% of all surveyed projects are considered to be successful and are delivered on time, on budget, with the required features and functions. This could be an indication that project management practitioners have not fully acquired and transferred knowledge learned from past projects to ensure a higher success rate for current and future projects.

Knowledge management is an emerging discipline and practice in organizations. This paper proposes an integrated model that combines knowledge management with project management to improve project success and thus contribute towards competitiveness and sustainability in organizations.

Keywords: Knowledge Management; Knowledge Transfer; Project Management; Project Lifecycle; Project Success

\section{Introduction}

Organizations today face dynamic market competitions and continuous technology advances, creating unique knowledge through innovation that leads to organizational sustainability in the marketplace. This innovative knowledge transforms into products and services that allow organizations to continue to grow and survive in the business. Products and services are the end results or deliverables of the several project initiatives of the organizations. Nonaka (1991) argues that successful companies are those that consistently create new knowledge, circulate knowledge within the organization and deploy the knowledge into new products rapidly. This paper reviews the definitions of knowledge management and project management-related terms from a number of internationally recognized guides or frameworks. This is followed by exploring literature in the area of integrating knowledge management with project management in order to improve the success rate of the projects. The paper then discusses the possibility of combining the knowledge management and project management frameworks to enhance project success and proposes such an integrated model. 


\section{Definitions of knowledge management}

Knowledge has been touted as the only asset that can offer organizations a competitive advantage as there is a strong linkage between core competence and knowledge (Prahalad \& Hamel 1990). Knowledge could be explored individually or as part of knowledge management or the knowledge management system concept. The concept of knowledge is explored by Seufert, Back and von Krogh (2003) as a continuous flow in which knowledge is categorized into logical processes such as localizing and capturing; sharing and transferring; creating and applying. They attempt to explain knowledge management as a process of managing knowledge to enable “creation of entirely new knowledge, while also accelerating the innovation” (Seufert et al. 2003: 106). Others have argued that knowledge management also contributes to productivity in a costcutting environment (Thompson 2003).

Several researchers agree that the main components of knowledge management include the dimensions of organizational culture, processes and technology (Lee \& Hong 2002; Chung et al. 2001). Bollinger and Smith (2001) acknowledge knowledge management as a resource in terms of what the organization knows about customers, products and processes, and resides in databases or is gained through the sharing of experiences and best practices both internally and externally (Bollinger \& Smith 2001).

Much of the work on knowledge management has been to focus on the components of knowledge management without much attention being placed on how the knowledge management processes are affected by other factors such as culture and technology. Linkages between organizational culture, context, structure, leadership and knowledge management processes can be established (Lim 2002).

\section{Definitions of project, project management and project success}

The Project Management Institute (PMI) is a widely recognized association by project management practitioners internationally. The PMI is prominent in the research and training of professionals in the United States but it also has a significant global presence. The Institute's Project Management Body of Knowledge guide (PMBOK) defines a project as being "a temporary endeavor undertaken to create a unique product, service, or result” (PMI 2008:4). A project can create a product that can be either a component of another item or an end item in itself (PMI 2008). Project management is defined as "the application of knowledge, skills, tools, and techniques to project activities to meet the project requirement” (PMI 2008:6).

There are alternate definitions of project and project management from other guides or frameworks. Other popular definitions are from the Managing Successful Projects with PRINCE2 guide. PRINCE2 is the acronym for Project in Controlled Environment version 2, a registered trademark from Office of Government Commerce from United Kingdom. PRINCE2 is a project management framework adopted mostly in European countries and Australia but lately gaining international popularity. According to the PRINCE2 guide, a project is "a temporary organization that is created for the purpose of delivering one or more business products according to an agreed business case (OGC 2009:16). Project management is defined as" the planning, delegating, monitoring and control of all aspects of the project, and the motivation of 
those involved, to achieve the project objectives within the expected performance targets for time, cost, quality, scope, benefits and risks” (OGC 2009:17).

The Project Management Association of Japan (PMAJ) offers yet another definition for project and project management. According to the PMAJ's Project \& Program Management guide (P2M), "project refers to a value creation undertaking based on a specific, which is completed in a given or agreed time frame and under constraints, including resources and external circumstances” (PMAJ 2005:15). The PMAJ defines project management as "the professional capability to deliver, with due diligence, a project product that fulfills a given mission, by organizing a dedicated project team, effectively combining the most appropriate technical and managerial methods and techniques and devising the most efficient and effective work breakdown and implementation routes” (PMAJ 2005:16). PMAJ and the Project \& Program Management guide are highly regarded by the project management professionals in Japan.

All three definitions of project and project management have similarities and complement each other.

According to the PMBOK, the increase in project management indicates that the application of appropriate knowledge, process, skills, tools, and techniques can have a significant impact on project success (PMI 2008). The main objective of project management is to ensure a project is be completed at the required scope defined by the stakeholders, within project budget, on time and delivers a quality product or service as the end result.

Managing Successful Projects with PRINCE2 offers a set of principles, themes and processes to deliver a successful project according to the business case. The business case, according to the guide, presents the optimum mix of information used to judge whether the project is desirable, remains desirable during the project lifecycle, is viable and achievable and, therefore, worthwhile investing in from the stakeholders' perspective (OGC 2009). PRINCE2 states that a key success factor of any project is that it delivers what the user expects and finds it acceptable (OGC 2009).

The P2M adds additional dimensions for the criteria of project success. It reasons that, in order to complete a project successfully, it is necessary to devise a well integrated plan that takes into account budget, time as well as HSE (health, safety, environment) aspects of the project (PMAJ 2005).

In general, project success can be judged as the project completed within time, cost and quality. However, Turner (2009) argues that this definition is simplistic and even dangerous (Turner 2009). He gives an example of a project that was finished on cost and in time but five years later was judged to be a failure. Turner states that different stakeholders, for example, sponsors, users and project managers, judge project success in different ways and it is important to achieve a balance of those different criteria, to meet the needs of the different stakeholders (Turner 2009). Kerzner (2009) agrees that it is one of the most difficult tasks to predict whether a project will be successful. Projects delivered on time, within cost and meeting performance requirements might contribute to profits but we may not be able to identify whether the project itself was managed correctly (Kerzner 2009). 
In addition to the traditional definitions of project success from other guides or frameworks, Turner (2009) lists nine criteria for judging project success

- "The project increases the shareholder value of the parent organization.

- The project generates a profit.

- The project provides the desired performance improvement.

- The new asset works as expected.

- The new asset produces a product or provides a service that consumers want to buy.

- The new asset is easy to operate.

- The project is finished on time, to budget, and with the desired quality.

- The project team has a satisfactory experience and the project met their needs.

- The contractors made a profit” (Turner, 2009:67).

Turner (2009) emphasizes that project success needs to balance the needs of everybody in the organization. The project success criteria focus on success as a whole. The top three points relate to higher-level strategic goals. The middle three points relate to the project's outcome on whether the project delivered what was expected. The last three points assess the works of the project as well as the outputs of the project (Turner 2009).

\section{Integrating knowledge management with project management}

The previous sections of the paper discussed the definitions of knowledge management and project management-related terms. This section explores the contemporary literature on integrating knowledge management and project management to improve project success in the organization.

According to Ismail et al. (2009), despite the extensive literature on knowledge sharing, little is known about how individuals share knowledge, especially in a project environment. The authors proposed a theoretical framework as represented in Figure 1, which indicates that providing appropriate motivators and removing relevant inhibitors to sharing knowledge and experience would result in more efficient and effective sharing of knowledge in projects which, in turn, would lead to an increased probability of project success. Their model suggests that there are significant relationships between effective project knowledge sharing practice and project success. The model was based on Nonaka's Knowledge Conversion Model ( known as the SECI model) and focuses on the socialization of tacit knowledge, which is currently a gap in most project environments. The authors concluded that ensuring when and how tacit and explicit knowledge is shared is essential for enhancing project success (Ismail et al. 2009). 


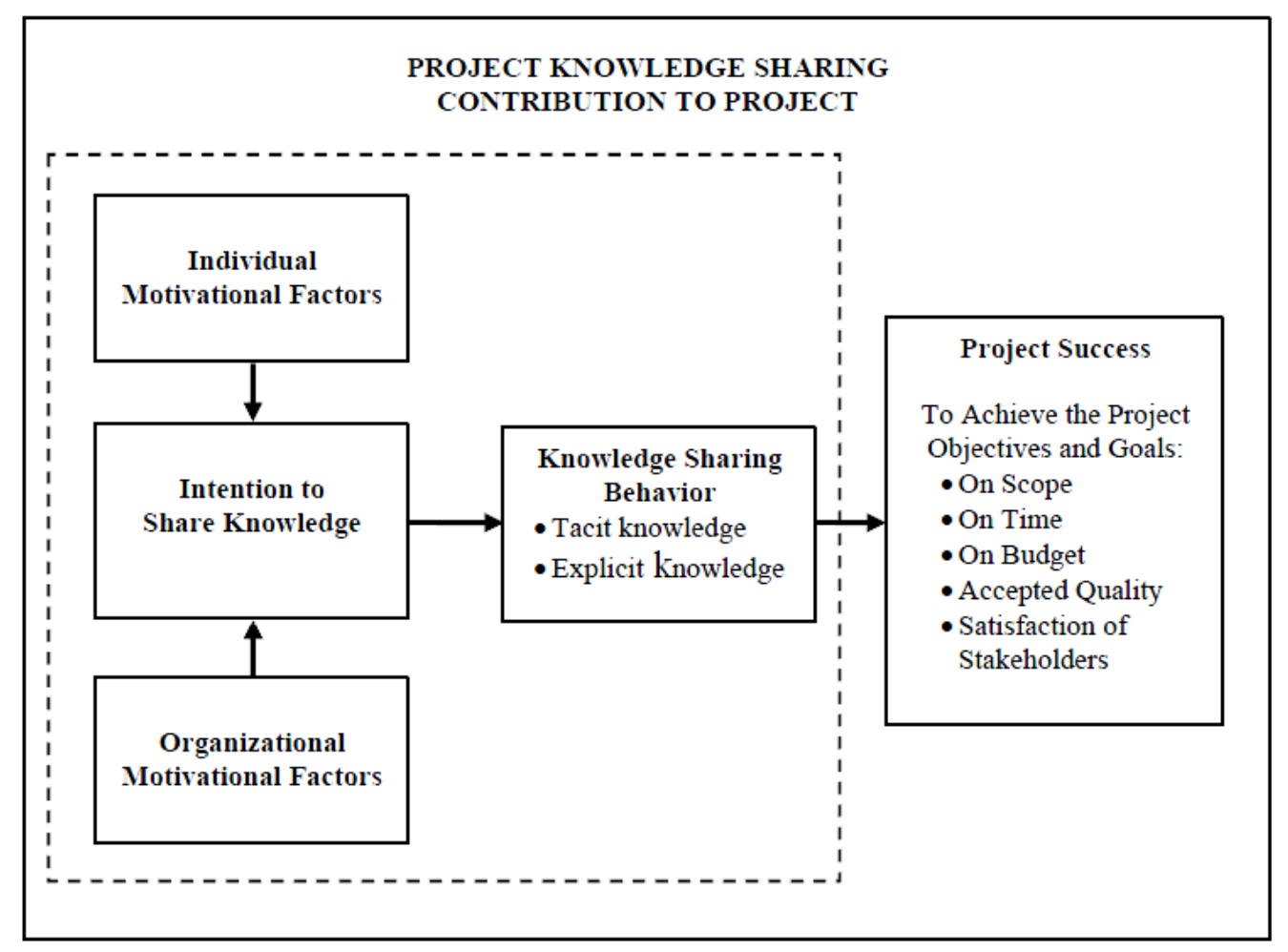

\section{Figure 1. Proposed theoretical framework for project knowledge sharing contribution to project}

Source: Ismail et al. 2009:52.

Cope III et al. (2006) also suggest that knowledge management is a practice that makes sense for improving project management. They state that if the knowledge (both tacit and explicit forms) could be captured and shared within the project management community, organizations would benefit a lot (CopeIII et al., 2006).

Lierni and Ribiere (2008) state that very few academic publications focus on the role of using knowledge management to improve the management of projects. Lierni and Ribiere conclude that it is reasonably certain that project managers perceive the use of knowledge management practices as a positive influence on the management of projects. The most frequently adopted knowledge management practices to help project managers are: Shared Repository of Project Artifacts; Lessons Learned and Best Practices Repositories; and Document and Content Management Systems (Lierni \& Ribiere 2008). They propose that in the project environments, knowledge comes primarily from explicit knowledge sources but project managers could strongly benefit from sharing and codifying tacit knowledge associated with the management of former projects.

Another framework, proposed by Owen (2008), is that knowledge created, transferred, captured and reused within a project will result in improving project management maturity. She provides a structure to link project/program management to knowledge management and mutually exploiting both (see Figure 2). According to her, a project can be defined as a task where knowledge is created as the result of the activities that are carried out by project teams. Project team members create, transfer, and reuse knowledge created from the tasks supported by a 
knowledge management system. This framework suggests that project team members will be able to conceptualize the task, and reuse and apply past knowledge and experiences supported by a knowledge management system.

Owen's framework shows how knowledge is developed at the task level which is embedded into the project methodology in the project environment and eventually improves the capability of an organization. She suggests that knowledge is embedded throughout the project lifecycle at both tactic and explicit levels. Tacit knowledge is captured and reused at the project level in the form of personal knowledge contributed by the project team members. Tacit knowledge is transferred and reused via mentoring from project members with more experience. Explicit knowledge is reused in terms of project documentation captured during the project lifecycle. The framework proposed by Owen uses the concept of recursiveness and extending the project to the program level, where the program is a group of projects managed together allowing added benefit and control which would not normally be achieved from managing the projects individually (PMI 2008; Owen 2008).

Owen concludes that in order for an organization to deliver successful projects, continuous learning needs to occur to improve its capability. Continuous learning can be derived in terms of developing guidelines for creating, sharing, and reusing knowledge in a project management environment, thus integrating knowledge management practices with project/program management.

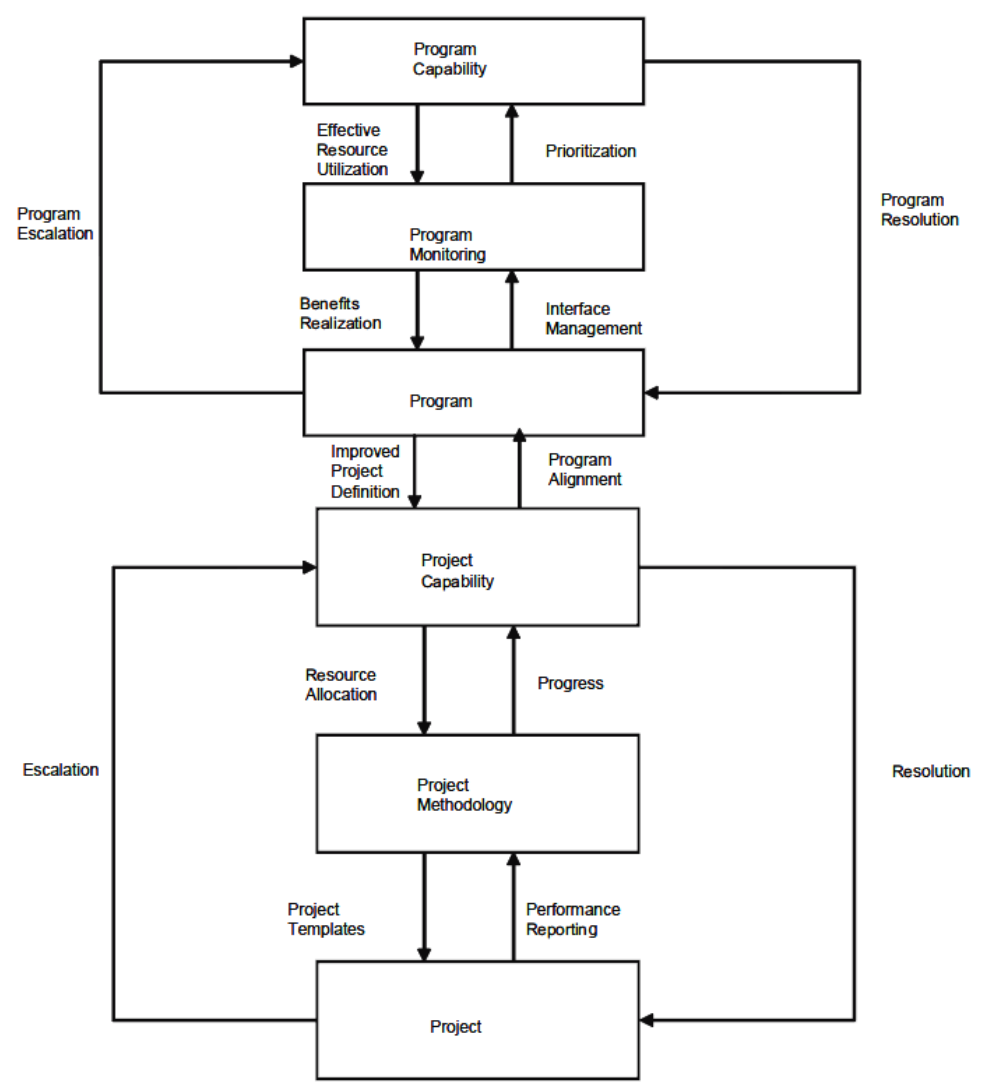

Figure 2. Knowledge management and project/program management linked 
Source: Owen 2008:140.

Finally, Gudi and Becerra-Fernandez (2006) studied the role of knowledge management in project management of complex systems organizations. Their research was driven by the motivation to reduce risk and prevent failures during the development of complex systems and focus on the dynamic aspects of project management using knowledge management. They argue that if we are able to understand the nature of risky systems better, we may be able to reduce or remove the risk of failure and increase the chance of project success. Gudi and BecerraFernandez suggest that when the project complexity increases, it becomes important to find the means to manage the inter-relatedness of sub-projects and related activities and events in the project environments. Their intent is to identify knowledge management strategies, which organizations could institute in project management practices to reduce risk of failure and increase the chance of project success.

Gudi and Becerra-Fernandez (2006) identified certain knowledge management mechanisms, processes and technologies that could be appropriate for project management requirements. Their conceptual model of the role of knowledge management in project management is summarized in Figure 3 below. They concluded that there are many factors affecting project risk in complex project organizations. These include external factors like political and economic impacts. The extent of innovation, complexity and coupling are some internal factors affecting project risk. Finally, knowledge management mechanisms and technologies influence project team adaptation which in turn affect project success (Gudi and Becerra-Fernandez 2006). Consistent with previous literature, project success is measured in terms of time, budget and functionality.

\section{Conceptual Model}

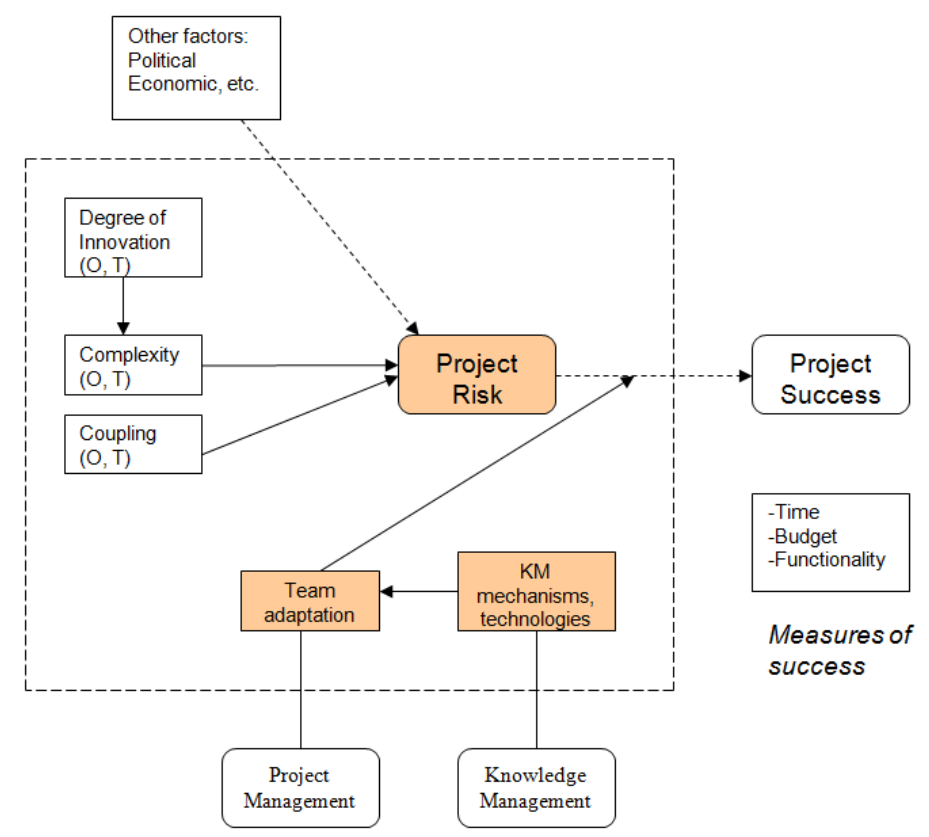

Figure 3. Role of knowledge management in project management

Source: Gudi \& Becerra-Fernandez 2006:26. 
As described by Levin (2010), every organization wants to make use of project management to deliver its products and services with superior outcomes and benefits that can be sustained for its customers and users. If the organization could implement knowledge management effectively, it is the key to success in project management and thus could transform the organization to excellence. Organizations are becoming project-based and management-by-projects is a defined strategy. However, in order for the organization to transform further, knowledge management must be integrated with project management to response rapidly to gather information to solve specific problems and share knowledge assets effectively and efficiently. Levin argues that knowledge management must become an integral part of each project professional's daily project work. She suggests that it is necessary to integrate knowledge bases to projects so the people involved in the project could combine individual contributions to those of the project's objectives and align with the organization's strategic objectives.

Levin proposes nine guidelines for organization to have successful implementation of integration of knowledge management with project management as listed below:

- Define knowledge management so that everyone in the organization can understand it

- Make knowledge management to be a work package in the work breakdown structure of every project

- Establish a point of contact for knowledge management on each program and project working with the Enterprise Project Management Office

- Use a Responsibility Accountability Matrix (RAM) to define roles, responsibilities, and accountabilities for knowledge management

- Communicate the importance of knowledge management to all stakeholders throughout the organization

- Provide knowledge management orientation and training to all stakeholders

- Establish a practical knowledge management reward and recognition system

- Track the usefulness of knowledge management by using metrics

- Organization should focus on continuous improvement (Levin 2010)

\section{Proposed integrated KM \& PM model}

In the previous section, the literature on knowledge management and project management was reviewed with the view to merging knowledge management and project management in order to improve project performance and knowledge sharing and ensuring project success.

A theoretical framework is now proposed based on the knowledge derived from the literature discussed in the previous section, which introduces the intervening factors that might influence knowledge management and project management. The intervening factors proposed in this paper are culture, process and technology. It is suggested that these factors might have an impact on knowledge management and project management factors which, in turn, influence the enhancement of project success. In a study undertaken by Lim (2008), it was found that organizational culture, knowledge management process and technology provide strong support for effective knowledge sharing. As indicated earlier, other researchers also agree that the main components of knowledge management include organizational culture, processes and technology (Lee and Hong 2002; Chung et al. 2001). 
Turner (2009) states that in order to speed up the delivery of new products, it is critical that new project management practices are introduced in the organization. These include the change of organizational culture and the use of new technology as well as the process that focuses on the quality of the project's deliverables. In the proposed theoretical framework for this paper, it is suggested that culture, technology and process might influence project management practices in the organization which in turn affect the chance of project success (see Figure 4).

Culture is the most significant problem in international projects as stated by Turner (2009). The dimensions of cultural difference according to Turner (2009) include:

- Uncertainty avoidance

- Power distance

- Individualism

- Masculinity

- Role of time

- Consideration of detail

Turner (2009) suggests that appropriate project managers and project team members should be selected to accommodate cultural differences in international projects. Appropriate leadership styles, methods of working, appropriate languages and cross-border coaches should also applied in managing international project with different cultures (Turner 2009).

The proposed theoretical model for this paper suggests that the culture is important to most project environments and not just international projects. This is supported by Kendra and Taplin (2004), who state that the alignment of organizational cultural values with project management values enables the organization to successfully adopt project management as a new work method for improved project success.

A process in a project environment is known as a structured set of activities designed to accomplish a specific organization's objective. A process has several defined inputs and turns them into defined outputs which are the deliverables of a project (OGC 2009). There are two versions of process (Turner 2009; PMI, 2008):

- Process derived from the work of Henri Fayol: plan, organize, implement and control.

- Process according to the PMBOK: initiate, plan, organize, execute, control and close.

The notion of process is similar to the phases in project lifecycle and the management of process has a significant impact on project success. Thus, process is one of the three key factors that affect the project environment and, in turn, project success in the proposed theoretical model.

Turner (2009) argues that good project management can be achieved by achieving a balance between the different areas of technology as well as between technology and culture (people, system and organization). In most projects, the project manager should be viewed as the person possessing an understanding of the technology rather than a command of the technology. Good project management practices emphasize a cooperative working relationship between the project manager and the technical experts from the line management (Kerzner 2009). 
Levin (2010) emphasizes that knowledge management must be embedded throughout the project management lifecycle. Knowledge assets are continuously developed in the organization and each project should builds on these and shares the knowledge (Levin, 2010).

In the proposed model (Figure 4), it is suggested that project managers should continuously feedback and align existing knowledge from the repository and newly created knowledge from the projects to enhance project success. This could be done by building the process to the project lifecycle and holding regular discussions to share knowledge with all project members and stakeholders.

In summary, two propositions have been derived from the theoretical model for this paper:

\section{Proposition 1}

Culture, process and technology are common factors influencing knowledge management and project management.

\section{Proposition 2}

Continuous feedback and alignment of knowledge management and project management enhances project success

KM in PM: Conceptual Model

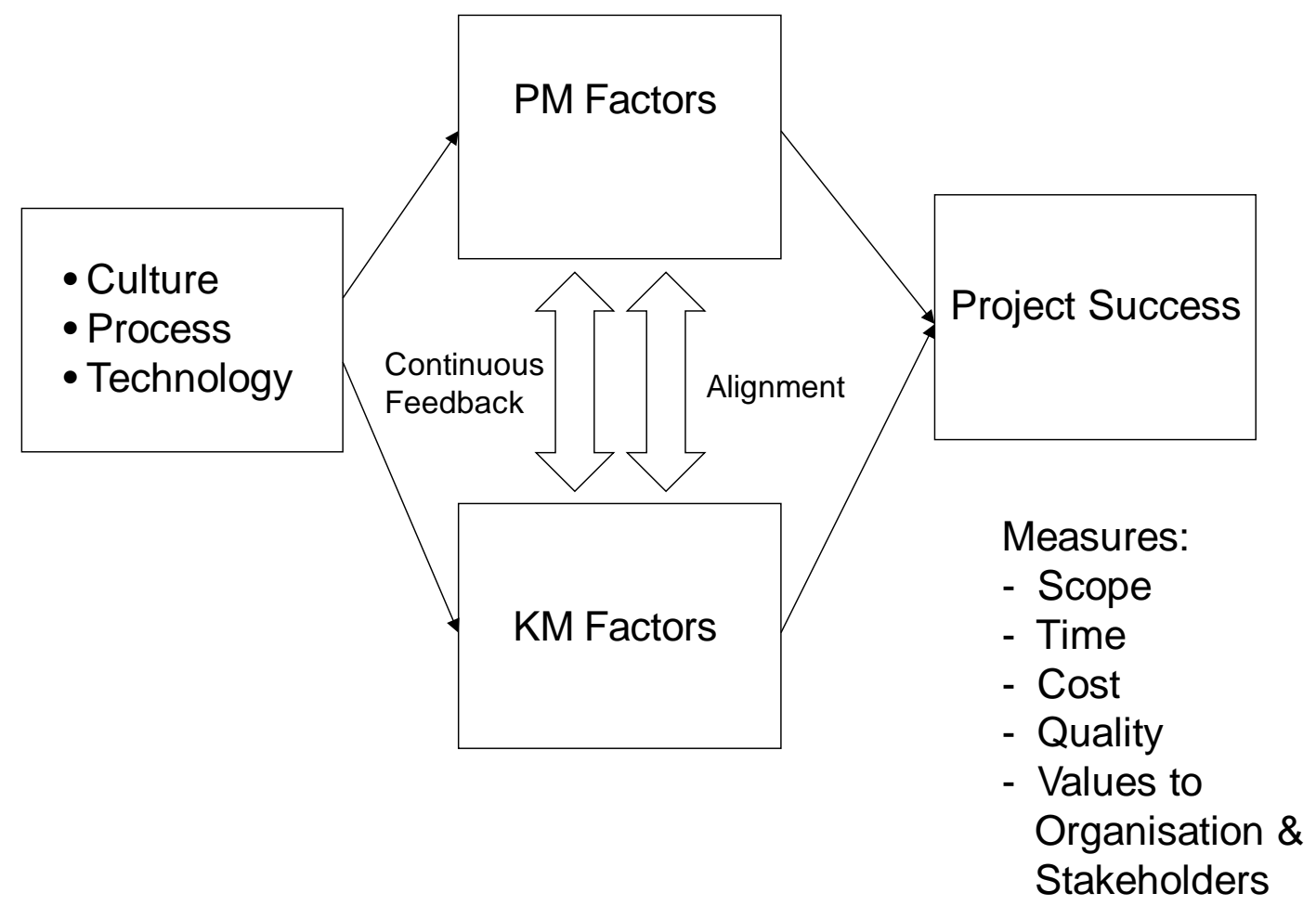

Figure 4. Proposed integrated knowledge management and project management model

Source: developed for this paper. 


\section{Conclusions}

The purpose of this paper is to understand the integration of knowledge management with project management to enhance project success in organizations. Definitions of knowledge management and project management-related terms have been discussed. Relevant literature in the areas of integrating knowledge management with project management was reviewed. It is important to understand how knowledge could be created via projects and how the knowledge is transferred to other project team members in the form of tacit and explicit knowledge. It is assumed that continuous feedback and alignment of knowledge in the project lifecycle as well as knowledge sharing among the project team members is essential for enhancing the success of a project. A theoretical framework is proposed to suggest that both knowledge management factors and project management factors could have significant influence on project success. The common factors are culture, process and technology that, in turn, might affect both knowledge management and project management. This emphasizes the need for continuous feedback and alignment of knowledge in the project environment. This paper contributes to both knowledge management and project management disciplines. It provides a foundation to conduct further research to understand how project success might be achieved via integrating knowledge management and project management as well as the underlying culture, process and technology factors. Future research could include a study of the capture and sharing of existing knowledge and new knowledge in all phases of the project lifecycle. To conclude, knowledge is created via projects and continuous creation of innovative knowledge is essential for the survival of organizations.

\section{References}

Bollinger, A.S. \& Smith, R.D. 2001, Managing organizational knowledge as a strategic asset. Journal of Knowledge Management, vol. 5, 8-18.

Chung, W.K., Har, S.S. \& Wah, C.K. 2001, Primer on Knowledge Management, Productivity and Standards Board, Singapore.

Cope III, R.F., Cope, R.F. \& Hotard, D.G. 2006,. Enhancing project management with knowledge Management principles, Allied Academies International Conference 2006, New Orleans, LA.

Gudi, A. \& Becerra-Fernandez, I. 2006, Role of knowledge management in project management of complex systems organizations, NASA Knowledge Management and Successful Mission Operations Conference 2006, Houston, TX.

Ismail, W.K.W., Nor, K.M. \& Marjani, T. 2009, The role of knowledge sharing practice in enhancing project success, Institute of Interdisciplinary Business Research, 1.

Kendra, K. \& Taplin, L.J. 2004, Project success: a cultural framework, Project Management Journal, vol. 35, no. 1, $30-45$.

Kerzner, H. 2009. Project Management — A Systems Approach to Planning, Scheduling, and Controlling, Wiley, New York.

Lee, S.M. \& Hong, S. 2002, An enterprise-wide knowledge management system infrastructure. Industrial Management \& Data Systems, vol. 102, no. 1, 17-25.

Levin, G. 2010, Knowledge mangement success equals project management success, PMI Global Congress 11 Oct 2010, Washington D.C.

Lierni, P.C. \& Ribiere, V.M. 2008, The relationship between improving the management of projects and the use of KM, The Journal of Information and Knowledge Management Systems, vol 38, no. 1, 133-146.

Lim, T.T. 2002, Organizational culture and knowledge management, Journal of Information and Knowledge Management, vol. 1, no. 1, 57-63. 
Lim, T.T. 2008, Organizational Culture and Knowledge Management. DBA thesis, Southern Cross University. Nonaka, I. 1991. The knowledge-creating company. Harvard Business Review, November-December 1991.

OGC (Office of the Government Commerce) 2009, Managing Successful Projects wih PRINCE2 ${ }^{T M}$, The Stationary Office, Norfolk, UK.

Owen, J. 2008, Integrating knowledge management with programme management, Jennex, M.E. (ed.), Current Issues in Knowledge Management, IGI Global, New York, 132-148.

PMAJ 2005, A Guidebook of Project \& Program Management for Enterprise Innovation.

PMI 2008, A Guide to the Project Management Body of Knowledge (PMBOK), Project Management Institute, Newtown Square, PA.

Prahalad, C.K. \& Hamel, G. 1990, The core competence of the corporation. Harvard Business Review, May-June 1990.

Seufert, A., Back, A. \& Krogh, G.V. 2003, Unleashing the power of networks for knowledge management: putting knowledge networks into action, in Beerli, A.J., Falk, S. \& Diemers, D. (eds), Knowledge management and networked environments: leveraging intellectual capital in virtual business communities, Amacom, New York, 99-136.

Thompson, E. 2003, Effective KM in a cost-cutting environment, KM Review, 6, 12-15.

Turner, J.R. 2009, The Handbook of Project-Based Management, Mc-Graw Hill, London.

\section{About the authors:}

Anthony Yeong is an independent consultant, trainer and researcher in project management from Sydney, Australia. Anthony has a DBA and MBA from Southern Cross University, Australia. He is an external supervisor registered with Southern Cross University with their doctoral business program. In addition, Anthony is a certified Project Management Professional (PMP) from PMI, US, and PRINCE2 Practitioner from APM Group, UK. His major research interests are project management, knowledge management, marketing management and consumer behaviour.

Email: anthony@anthonyyeong.com

Thou Tin Lim is the principal consultant at Decision Modelling Systems. He is a certified business intelligence professional in business analytics with TDWI and a fellow of the American Academy of Financial Management. As a management consultant and practitioner, he has facilitated organizational initiatives/projects over 15 years in the region, including Australia, China, Singapore, Malaysia, Mauritius, India, Indonesia and Thailand. Thou Tin holds Masters degrees in Information Systems and Knowledge Management and a DBA from Southern Cross University, Australia. His current research interests include business modelling and business intelligence. He has published articles in refereed international journals, and book chapters in the area of business intelligence, management research and knowledge management.

Email: limtt@dms-consultancy.com 